A R T I G O

\title{
PORTUGAL BUILDS: UMA PLATAFORMA DIGITAL PARA A HISTÓRIA DA CONSTRUÇÃO EM PORTUGAL NOS SÉCULOS XIX E XX
}

Portugal Builds: a digital knowledge platform for the history of construction in Portugal 19th-20th centuries

Portugal Builds: una plataforma digital para la historia de la construcción en Portugal en los siglos XIX y XX

JOÃO MASCARENHAS MATEUS ${ }^{*}$

IVO VEIGA $\mathrm{I}^{* *}$

DOI: http://dx.doi.org/10.1590/S2178-14942020000100006

\footnotetext{
'Universidade de Lisboa, Lisboa, Portugal.

* Investigador principal FCT do Centro de Investigação em Arquitetura, Urbanismo e Design (Ciaud) da Faculdade de Arquitetura da Universidade de Lisboa (joao.m.mateus@fa.ulisboa.pt). ORCID ID: http://orcid.org/0000-0002-9910-6328.

** Investigador auxiliar, Faculdade de Arquitetura da Universidade de Lisboa e membro associado do IHC, Nova FCSH (ivoveiga@fa.ulisboa.pt). ORCID ID: http://orcid.org/0000-0001-8385-3030.
}

Artigo recebido em 31 de julho de 2019 e aprovado para publicação em 3 de dezembro de 2019. 


\title{
RESUMO
}

São apresentados os procedimentos da criação de uma plataforma digital de acesso gratuito destinada à disseminação dos resultados da investigação no campo da história da construção em Portugal, durante os séculos XIX e XX. Depois da descrição das fontes das coleções digitais, procede-se à análise da metodologia usada em sua estruturação e nas adaptações às singularidades desse campo de conhecimento de discussão recente. 0 estudo é ilustrado com a primeira exposição virtual, avaliando potencialidades e limites da plataforma para diferentes níveis de pesquisa no espaço e no tempo, relativas a atores individuais e coletivos e a objetos concretos e abstratos.

PALAVRAS-CHAVE: Coleções digitais; História digital; História pública; História da construção; Análise de redes; Portugal.

\begin{abstract}
The study aims to discuss the procedures for the creation of an open access digital platform to the dissemination of historical findings on construction history in Portugal, from $19^{\text {th }}$ to $20^{\text {th }}$ centuries. Digital collections description is followed by the methodology used to set the platform structure and the adaptations introduced to consider the singularities of this new field of knowledge. The paper is illustrated with the first virtual exhibition allowing an evaluation of the platform's potential and the limits at different levels of research in time and space, relating individual and collective actors, as well as concrete and abstract objects.
\end{abstract}

KEYWORDS: Digital collections; Digital history; Public history; Construction history; Social network analysis; Portugal.

\section{RESUMEN}

Este artículo analiza los procedimientos de creación de una plataforma digital de acceso libre para diseminación de resultados de pesquisa sobre la historia da la construcción en Portugal, en los siglos XIX-XX. A la presentación de las colecciones digitales se sigue la discusión de la metodología usada en su estructuración y las adaptaciones a las singularidades del nuevo campo de conocimiento. El estudio es ilustrado con la primera exposición virtual, evaluando potencialidades y límites de la plataforma para diferentes niveles de pesquisa en el espacio y en el tiempo, relacionando actores individuales y colectivos y objetos concretos y abstractos.

PALABRAS CLAVE: Colecciones digitales; Historia digital; Historia pública; Historia de la construcción; Análisis de redes; Portugal. 


\section{INTRODUÇÃO}

$\bigcup_{\text {importa definir estratégias sustentáveis de investigação que exponham objetos digitais }}^{\text {este tempo em que se abrem múltiplas possibilidades de obter e analisar dados históricos, }}$ de uma forma publicamente acessível e conceitualmente argumentada. Este texto pretende discutir os principais procedimentos levados a cabo na disponibilização em linha de coleções digitais e, assim, contribuir para a definição de projetos digitais de história pública. Todos os argumentos são construídos a partir de um projeto de pesquisa sobre a história da construção em Portugal nos séculos XIX-XX.'

0 projeto enquadra-se no esforço internacional de dar corpo à história da construção e torná-la uma disciplina autônoma. Assume-se que, para analisar a história do modo como se construiu em Portugal em uma perspetiva histórica e espacialmente situada, importa recorrer ao conceito de cultura construtiva proposto inicialmente por Jane Morley (1987: 19), retomado e reajustado posteriormente por Howard Davis (2006: 5): "The culture of building is the coordinated system of knowledge, rules, procedures, and habits that surrounds the building process in a given place and time." Nesse sentido, examinar a história das culturas construtivas em Portugal implica revisitar as principais fases da transformação do conhecimento, dos processos e dos habitats a elas associadas, de forma a tornar compreensível as "transformações históricas ocorridas nos materiais, modos e gramáticas da construção no território continental português" (Mascarenhas-Mateus, 2013).

0 projeto PTBuilds, dedicado à criação de uma plataforma digital sobre a história da construção em Portugal nos séculos XIX e XX, ${ }^{2}$ que se encontra em fase de elaboração, procura contribuir para a análise de novos dados empíricos desse campo do conhecimento, ainda pouco explorado. A utilização de meios digitais permite potenciar a disseminação dos resultados de investigação da história da construção, tal como as próprias humanidades digitais. Pretende-se, assim, demonstrar que as ferramentas digitais são um instrumento heurístico útil para o desenvolvimento de novas abordagens historiográficas. Para além disso, o recurso à contribuição colaborativa, por meio do sistema de gestão de conteúdos Omeka, ${ }^{3}$ pode auxiliar na integração de informação dispersa sobre os atores do setor da construção, que, na maior parte das vezes, têm sua investigação histórica limitada a pequenos portfólios confinados no espaço e tempo. Assim, a colocação de exposições temáticas na plataforma, nomeadamente a primeira, que é dedicada à história das grandes empresas construtoras de obras públicas ativas em Portugal no final do século $X X^{4}$ pretende servir como estímulo, ou provocação, a um setor que produz conhecimento histórico de forma dispersa e fragmentada. Ficarão a ser conhecidas com mais rigor as transformações de um setor de atividade que, em Portugal, 
contribui para uma percentagem significativa das emissões de gases com efeito estufa, que tem um peso importante em seu produto interno bruto (PIB) e constitui parte significativa de sua população ativa. ${ }^{5}$ Nesse sentido, a plataforma constitui-se em um repositório interativo útil à discussão do desenvolvimento sustentável do setor da indústria da construção, à proteção do patrimônio cultural e às políticas de gestão do território e da paisagem. Estudar a história da construção é também contribuir para o capital de conhecimento necessário à implantação de estratégias de sustentabilidade, com a utilização de dados históricos por parte de empresas, de investigadores, de educadores e de outros utilizadores diversificados. 0 presente estudo é focado no processo de estruturação da plataforma digital (Figura 1), e, por essa razão, a maioria das imagens da primeira exposição virtual, que é consequência direta dessa formulação inicial aqui descrita em detalhe, só é colocada no fim do texto, de modo a ilustrar a concretização da abordagem analítica.

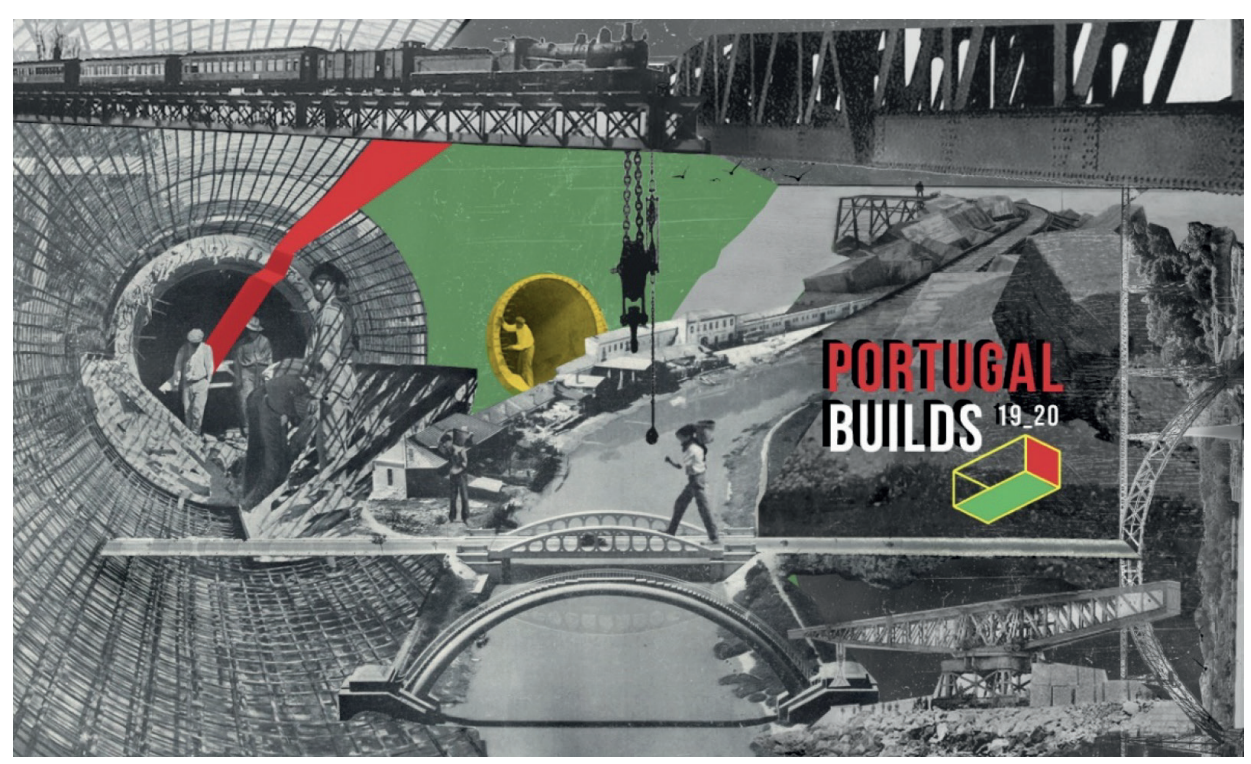

Figura 1 - Página inicial da plataforma: <http:// www.portugalbuilds.org>.

\section{MÉTODOS E INSTRUMENTOS DIGITAIS PARA A HISTÓRIA DA CONSTRUÇÃO}

O modo de produzir o conhecimento histórico, como resultado da disseminação das fontes e dos instrumentos digitais, está a transformar-se de forma acelerada. 0 uso da computação nos domínios disciplinares da história não é novo, nem é nova a mudança de escalas de 
análise que ela possibilita (Lemercier, 2015a). Contudo, a disponibilidade crescente de dados massivos sob forma digital implica o desenvolvimento de ferramentas que otimizem seu uso. Por essa razão, vários historiadores têm vindo a chamar a atenção para as oportunidades do tratamento de dados históricos massivos (Guldi e Armitage, 2014; Krakauer et al., 2018). Nesse sentido, a criação de novas infraestruturas tem tido, recentemente, um grande desenvolvimento. Para dar apenas alguns exemplos, são de referir o Seshat: Global History Databank ${ }^{6}$ ou a Europeana, ${ }^{7}$ a disponibilização de vastos arquivos digitais com instrumentos analíticos, como o History Lab, da Universidade de Columbia, ${ }^{8}$ ou a utilização de dicionários históricos biográficos com ampla informação (De Paiva et al., 2014). Com esses instrumentos, investigadores e usuários passaram a poder explorar objetos de estudo que cobrem décadas ou mesmo séculos, relacionando-os sob diferentes tipos, formatos e suportes - imagens, vídeos, gráficos, diagramas e mapas. As muitas técnicas digitais atualmente disponíveis permitem também que informação ligada à micro-história esteja cada vez mais presente na investigação de problemáticas complexas (Putnam, 2016).

Sem dúvida, os cruzamentos disciplinares, a utilização de novas metodologias para dados interligados de grande dimensão (Bearman, 2015; Strausser e Edwards, 2017) e o uso de diferentes escalas de análise são opções promissoras nas modalidades de investigação no período historiográfico atual. Uma das nobres tarefas dos historiadores - " identificar uniformidades e diferenças na experiência humana por forma a fazer comparações significativas no espaço e no tempo" (Boldizzoni, 2011) — fica também mais facilitada com as capacidades atuais da digitalização. Por outro lado, essas novas metodologias de análise de dados digitais permitem não só examinar invariantes como questionar as fronteiras comparativas. É o caso da análise de redes sociais e da abordagem espacial. ${ }^{9}$

A análise de redes sociais e o movimento de espacialização da história transnacional permitem colocar hipóteses, mudar escalas e prioridades, perspectivar erros e dar maior robustez e sistematização aos dados (Lemercier, 2015b; Struck, Ferry, e Revel, 2011). A abordagem dessas problemáticas, que conduzem ao estudo das sociedades como redes de relações multiescalares, encontra suas raízes em uma já venerável e antiga tradição de estudo, não só nos exercícios de história transnacional propostos por autores como Max Weber (1978) ou Fernand Braudel (1992), como também na análise de redes sociais desenvolvida por trabalhos como os de George Simmel (1971). Se o mundo contemporâneo é tecido em uma rede complexa de relações comerciais e intelectuais, se a história local está ligada à global, se as ideias e os bens não estão confinados aos limites das nações, ou seja, se uma nova configuração dos objetos históricos permite olhar para uma história global e transnacional, então essas trans- 
formações abertas pela tecnologia dilatam a amplitude do trabalho e atribuem-lhe uma forte base empírica. Nesse âmbito, vários grupos de investigação internacionais que têm dados digitalizados em larga escala têm aplicado essas metodologias. Mencione-se, por exemplo, o projeto Mapping the Republic of Letters (Edelstein et al., 2017), desenvolvido em parceria pela Universidade de Stanford. Entre vários estudos de caso, é possível constatar como muitos projetos têm-se beneficiado das capacidades analíticas da análise de redes sociais, recorrendo aos metadados e repensando os limites das histórias nacionais.

O setor da construção, por sua escala, processos de difusão tecnológica e técnica, envolvimento com os campos econômico, social e político, constitui um campo perfeito para explorar a relação entre as escalas global, nacional e local, as múltiplas relações de atores individuais e coletivos e as complexas relações dos atores com os artefatos históricos. Para além disso, transcendendo histórias nacionais e interpretações locais e regionais, é possível lançar pontes para projetos futuros no âmbito das várias associações nacionais dedicadas à história de como se construiu em determinado momento histórico e em dado lugar. ${ }^{10}$

Nos últimos anos, têm surgido muitas coleções digitais, ligadas a história, patrimônio ou instituições culturais. ${ }^{11}$ A própria Europeana tem seguido esse princípio das coleções e exposições. ${ }^{12}$ Nesse caminho digital, iniciado em outras áreas do conhecimento, junta-se agora o projeto PTBuilds, dedicado à história da construção. Com base em um vasto levantamento de fontes digitalizadas já iniciado em um projeto anterior, ${ }^{13}$ procura formular novas hipóteses e estabelecer relações entre objetos históricos que anteriormente não foram feitas no campo da construção. Para isso, desenvolve, com base no sistema de gestão de dados Omeka, várias coleções destinadas à apresentação de exposições virtuais em linha. Nesse campo de conhecimento, os dados obtidos poderão ser questionados de forma mais complexa e relacional. Quem foram os atores mais proeminentes no campo da construção ao longo dos séculos XIX e XX? Que relações estabeleceram entre si? Que relações se podem estabelecer entre obras e atores? Quais foram os mecanismos responsáveis pelos vários processos de mudanças de paradigmas técnicos e tecnológicos? Como essas redes de relações foram evolucionando no espaço e no tempo?

\section{AS FONTES DAS COLEÇÕES DE DADOS}

heterogeneidade dos dados passíveis de integrar um projeto no âmbito da história da
construção exige um critério de seleção das fontes e uma ponderação de suas consequências no nível da análise. Os dados de base disponibilizados pelo projeto anterior, já referido, e destinados à plataforma reúnem informação fundamental sobre as mais importan- 
tes transformações do setor da construção ocorridas em Portugal durante os séculos XIX e XX, no campo do ensino da engenharia e da arquitetura, na organização das várias corporações de profissionais, nos materiais, processos e máquinas usados nas construções, na legislação e na divulgação periódica e generalista. Inclui a recolha sistemática de dados estatísticos, biografias de engenheiros, arquitetos e construtores e informação sobre as características físicas e construtivas das principais obras públicas realizadas nesse período. Os dados consistem em cerca de 28.444 imagens em formato digital e .pdf, que correspondem a cerca de 10 mil artigos ou partes de artigos de periódicos, capítulos de livros e imagens, e a cerca de 2 mil citações e verbetes. Todos esses dados ocupam cerca de 100 Gigabytes, que se encontram armazenados em dois discos rígidos externos e em um disco em linha associado a uma conta Google. Nesses dados, recolhidos durante três anos por uma equipe de dois investigadores, estão incluídas também listas de hiperligações de arquivos em formato de vídeo. A importância desse volume de dados exige apenas ser completado pontualmente, quando necessário, no presente projeto.

As coleções digitais que alimentam a plataforma tiveram origem em diferentes arquivos e em diferentes formatos: documentos escritos, fotografias, filmes e registros de áudio. No que se refere a documentos escritos, devem-se salientar os anúncios comerciais de materiais de construção, as monografias científicas e de propaganda, os relatórios, as estatísticas, os decretos-leis e regulamentos para o setor da construção civil e obras públicas produzidos por instituições públicas e privadas (Ministério das Obras Públicas, Associação Industrial Portuguesa, Instituto Nacional de Estatística, Instituto de Propriedade Industrial), as monografias e os periódicos de engenharia, como Técnica, Revista de Obras Públicas e Minas, Revista de Engenharia Militar, revistas de arquitetura (A Construção Moderna, A Arquitectura Portuguesa, Revista Oficial do Sindicato Nacional dos Arquitectos, Binário), ou ainda a revista Indústria Portuguesa e a Gazeta dos Caminhos-de-Ferro. Entre os arquivos consultados, mencionem-se a Biblioteca e Arquivo Histórico do Ministério das Obras Públicas (hoje integrado ao Ministério da Economia), o Arquivo Nacional da Torre do Tombo, as bibliotecas das Ordens dos Arquitetos e dos Engenheiros, o Sistema de Informação para o Património Arquitetónico, a Biblioteca Nacional Digital, o Arquivo Fotográfico Municipal de Lisboa, o Centro Português de Fotografia, a Cinemateca Nacional, o Arquivo da Rádio Televisão de Portugal. Os documentos cartáceos introduzidos na plataforma foram digitalizados com o recurso a scanners, e seus conteúdos podem ser pesquisados beneficiando-se de OCR (Optical Character Recognition), ajudando, por exemplo, a procurar referências a determinados atores ou objetos nas dezenas de milhares de documentos à disposição. 


\section{O PROJETO PTBUILDS}

O principal objetivo do projeto é a criação de uma plataforma digital de conhecimento de acesso aberto dedicada à história do setor da construção em Portugal nos séculos XIX e XX. Nos dois séculos de história portuguesa que nos interessam, assistiu-se a uma mudança de paradigma entre as culturas construtivas milenares, baseadas na cal, e as novas culturas construtivas do aço, cimento Portland e vidro (Mascarenhas-Mateus, 2016a; Tostões, 2015). Esse câmbio iniciou-se por um período de experimentação e de otimização semi-industrial da cultura das alvenarias de pedra e cal e dos sistemas mistos de madeira-ferro e alvenarias, que foi muito sustentada pela necessidade urgente de reconstruir as zonas destruídas pelo grande terramoto de Lisboa de 1755. A transformação prosseguiu com a institucionalização do ensino no nível das academias e com a introdução do modelo politécnico, o controle de parte significativa das indústrias produtivas e do comércio por parte do Reino Unido — como a fabricação do vidro ou do ferro - , bem como com as primeiras importações de cimento Portland e a construção da rede ferroviária. A esse período seguiu-se outro, de formato nacional, caracterizado pelo controle da produção industrial dos materiais de construção, fundamentalmente na primeira metade do século XX, com as primeiras obras que utilizaram o sistema Hennebique de concreto armado, a implementação das cimenteiras portuguesas, a criação da rede elétrica nacional, da Companhia Portuguesa de Fornos Eléctricos e, posteriormente, da Siderurgia Nacional, já na década de 1960. Convém sublinhar, todavia, que em resultado de uma industrialização débil e um desenvolvimento socioeconômico pouco robusto, as culturas construtivas da pedra e cal das zonas rurais continuaram a coexistir com o betão armado das cidades e zonas industriais (Mascarenhas-Mateus, 2016b). Só nas décadas de 1970-1980 a indústria cimenteira portuguesa tornou-se dominante em todos os setores da construção, tornando residual a cultura da cal.

Com a plataforma digital, procura-se cruzar esses processos históricos, que se movimentaram a diferentes ritmos, constituindo-se, assim, um instrumento fundamental para tornar acessível a informação (estatísticas, mapas, gráficos, imagens fotográficas, vídeos e links) indispensável para compreender a atuação de todos os agentes envolvidos na execução das construções e em sua apresentação a públicos especializados ou ao grande público: indivíduos, empresas, instituições e associações.

Importa acrescentar que, para além de colocar em acesso aberto a história dos últimos dois séculos de um dos mais importantes setores de atividade econômica portuguesa, o projeto relaciona não só atores, mas também objetos e processos históricos pouco explorados pela comunidade acadêmica portuguesa. Considerando, em particular, o período em que o aço e 
o betão tornaram-se sistemas construtivos incontornáveis, a plataforma "Portugal Builds séculos XIX-XX/19th-20th centuries" mapeia diferentes objetos históricos georreferenciados em diversos níveis de análise: indústrias extrativas e transformadoras de materiais de construção, grandes infraestruturas em ferro e aço (pontes, viadutos, gares e equipamentos vários de ferrovias, estradas, barragens, portos, pavilhões industriais e núcleos urbanos), construções em concreto armado de referência (cais de embarque, tanques, edifícios fabris, habitacionais etc.), construções em concreto pré-esforçado, em concreto pré-fabricado etc.

Assim, cada objeto histórico é associado ao contexto de sua produção, relacionando entre si os âmbitos local, regional e nacional, o que permite perceber o impacto das mudanças tecnológicas e técnicas globais na cultura das comunidades em Portugal. Uma vantagem analítica, que se traduz em uma melhor compreensão dos processos de transferência e troca. A aplicação de diferentes níveis de análise é, para além disso, relevante para estudar as redes sociais, ou seja, os padrões das interações entre os atores do setor da construção. Por exemplo, pode ajudar-nos a compreender a posição de um ator no seio de uma rede complexa, ou, para dar outro exemplo, ajudar a clarificar as relações entre múltiplas organizações de empresas e de profissionais. De forma sintética, as unidades de análise são estabelecidas temporalmente a várias escalas do território, de objetos e de atores, conduzindo a relações e padrões próprios da história da construção.

\section{A CRIAÇÃO DA PLATAFORMA DIGITAL E A CLASSIFICAÇÃO DOS DADOS}

Existem muitos textos dedicados à apresentação de plataformas digitais, mas não é comum forma constitui um critério fundamental para sua elaboração. Por outro lado, espera-se que o tema não se esgote nos produtos de história pública digital previstos e que atinja não só estudiosos acadêmicos e empresariais, como também decisores do próprio setor da construção. Por esse motivo, como mais à frente será explicado, procurar-se-á entender sua recepção junto a públicos diversos. No caso do projeto PTBuilds, a simplicidade de uso foi igualmente considerada prioritária na arquitetura geral da plataforma, para garantir a máxima acessibilidade e consulta da informação pelos diversos públicos. A escolha de duas línguas — português e inglês - insere-se no objetivo do projeto de não se confinar às realidades nacionais e servir a propósitos comparativos com a história da construção internacional. A plataforma está alojada nos servidores da empresa Reclaim Hosting, ${ }_{1}^{14}$ que é especializada nesses serviços nos setores acadêmicos e da pesquisa, e permanecerá acessível mesmo depois de o projeto estar 
concluído, reduzindo o número de entidades intermediárias para garantir sua manutenção. Com o servidor alojado no Reclaim Hosting, tornou-se mais ágil a instalação do sistema de gestão de conteúdos Omeka, pois se passou a ter acesso ao software necessário para que ele funcione - Linux, Apache, MySQL e PHP. Os ficheiros e pastas são alojados em uma diretoria do servidor, no qual também se podem gerir os módulos de extensão (ferramentas que complementam as funcionalidades nativas do sistema).

Existe uma vasta oferta de sistemas de gestão de conteúdos que poderiam, em potência, servir aos propósitos desse projeto. No entanto, optou-se pela escolha de uma solução que desse garantias de rigor e de manutenção e que ao mesmo tempo pudesse oferecer uma personalização focada na apresentação de resultados de investigação científica nos campos da história e das artes. Nesse âmbito, o Omeka é uma plataforma muito usada por instituições culturais e museus, que permite colocar em linha coleções e exposições virtuais, baseando-se na utilização funcional do esquema de metadados Dublin Core ${ }^{15}$ (Figura 2). 0 sistema consiste em uma família de produtos — Omeka Classic, Omeka.net e Omeka S —, com diferentes funcionalidades. Para o projeto, escolheu-se o Omeka Classic, que tem uma grande flexibilidade no nível da adoção de módulos de extensão e é mais dirigido a projetos individuais e pequenas equipes, por oposição ao Omeka S, orientado ao uso de instituições.

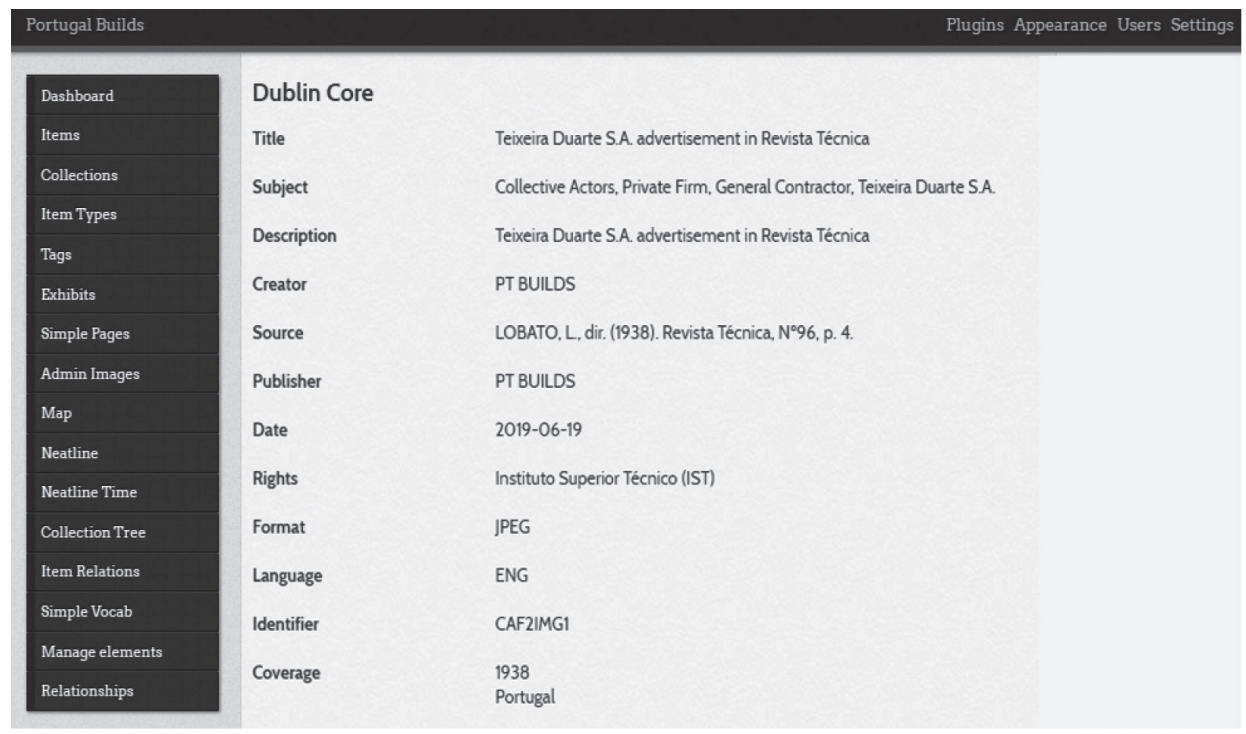

Figura 2 - Exemplo do preenchimento das 15 propriedades do Dublin Core, no sistema Omeka, para uma das empresas integradas na primeira exposição virtual da plataforma. 
Em uma primeira fase, foram mapeados centenas de sítios de instituições acadêmicas e culturais, com o objetivo de reconhecer boas práticas de utilização desse sistema na relação com seus públicos. Com esse fim, optou-se por desenvolver os elementos gráficos a partir do tema The Daily, recorrendo à programação nas linguagens CSS e PHP para personalizar alguns dos aspectos da apresentação dos conteúdos oferecidos pelo Omeka.

Remetendo à estrutura de organização dos museus, na utilização do Omeka está subjacente a ideia de criação de "coleções contextualizadas cuja curadoria é realizada por meio do sistema" (Shintaku et al., 2018: 53). Um Item é a unidade digital de base do Omeka. Uma Coleção é um conjunto de Itens. A Exposição, organizada por páginas, permite usar os Itens das Coleções para fins temáticos e analíticos, embora não seja uma funcionalidade de origem do Omeka e exija o módulo de extensão Exhibit Builder. Também é possível recorrer às etiquetas (Tags) para categorizar os Itens.

Para além das possibilidades referidas, o Omeka foi escolhido também por permitir a instalação de módulos de extensão desenvolvidos pela comunidade de usuários do sistema, possibilitando uma gestão mais eficiente da plataforma e uma melhor flexibilidade e atualização das ferramentas de navegação acessíveis aos usuários. Para além do já referido Exhibit Builder, foram igualmente instalados os seguintes módulos de extensão: Collection Tree, que permite organizar as Coleções de forma hierarquizada; Item Relations, que permite estabelecer relações entre Itens, usando o número de identificação do Item criado pelo sistema; Geolocation, que possibilita a atribuição de uma localização aos Itens por meio de mapas; Neatline e Storytelling, que garantem a georreferenciação, mostrando as mudanças espaciais, tendo em conta a variação temporal e criando anotações de imagens.

Procurou-se, igualmente, que as possibilidades de navegação fossem ao encontro das preferências dos usuários, oferecendo a exploração das coleções de Itens ou a orientação da pesquisa para determinados Itens. Assim, para além de um vocabulário mais controlado ligado à linguagem nativa, foi possível usar instrumentos interativos, como a análise de redes ou cronologias de eventos com base em critérios espaciais e temporais.

Tendo em conta o exposto, e antes de se proceder à implementação da plataforma, foi necessário desenvolver um trabalho conceitual, para ajustar as exigências dos objetos históricos relacionados com a história da construção ao esquema de metadados considerados pelo Omeka. Sem dúvida, alguns modelos de dados procuram captar toda a variação dos objetos históricos e estão, simultaneamente, interessados em examinar sua representação. Um bom exemplo é o projeto SyMoGIH - Système Modulaire de Gestion de I'Information Historique, que desenvolveu um modelo genérico de armazenamento para garantir a interoperatividade 
de dados de diferentes projetos, com diferentes abordagens disciplinares (Beretta, 2017). Contudo esses modelos mais genéricos, que têm sua raiz em um nível elevado de agregação dos dados, implicariam um esforço excessivo no nível do tratamento dos dados em um projeto com a escala e amplitude do PTBuilds. Por essa razão, a informação foi formalizada de maneira sistemática, fiável e replicável no âmbito dos objetos e atores relacionados com a história da construção. Assim, a plataforma PTBuilds foi estruturada em quatro grandes objetos de análise: 1) Atores Individuais; 2) Atores Coletivos; 3) Objetos Concretos; e 4) Objetos Abstratos, que correspondem às quatro Coleções principais da plataforma. Essas quatro categorias de objetos foram revistas e afinadas gradualmente, conduzindo a uma conformação estável de subcategorias.

\section{ATORES E OBJETOS NO ESPAÇO E TEMPO}

$\bigcup_{\text {ou coletivos. }}^{\text {aturalmente, uma história da construção é habitada por atores — sejam eles individuais }}$

\section{1) Atores Individuais}

Engenheiros, arquitetos e acadêmicos, apenas para dar alguns exemplos, povoam o espaço da história da construção. São eles que empreendem iniciativas, registram patentes e ensinam nas escolas e universidades. Pode-se, na verdade, contribuir para uma história social das elites a partir do estudo da atividade de atores como engenheiros e arquitetos. No entanto, outros atores frequentemente deixados na sombra não podiam deixar de ser considerados na plataforma PTBuilds (Figura 3). Assim, integrou-se também o contributo dos profissionais que trabalham em contato direto com as obras, salientando os construtores e os mestres de obras e considerando ofícios como os de pedreiro, carpinteiro, serrador ou forneiro. Essa abordagem permite resgatar também aspectos menos conhecidos, como a importância do trabalho das mulheres em certas atividades, tais como o transporte de argila para a indústria cerâmica tradicional e de concreto para as primeiras pontes Hennebique realizadas em território português. Por essa razão, para os Atores Individuais, foram criadas as subcategorias: Empreendedor, Político, Funcionário Público, Técnico (Engenheiro Civil/Militar, Arquiteto, Mestre de Obras), Acadêmico (Professor, Investigador), Trabalhador (carpinteiro, mecânico, manual etc.). 

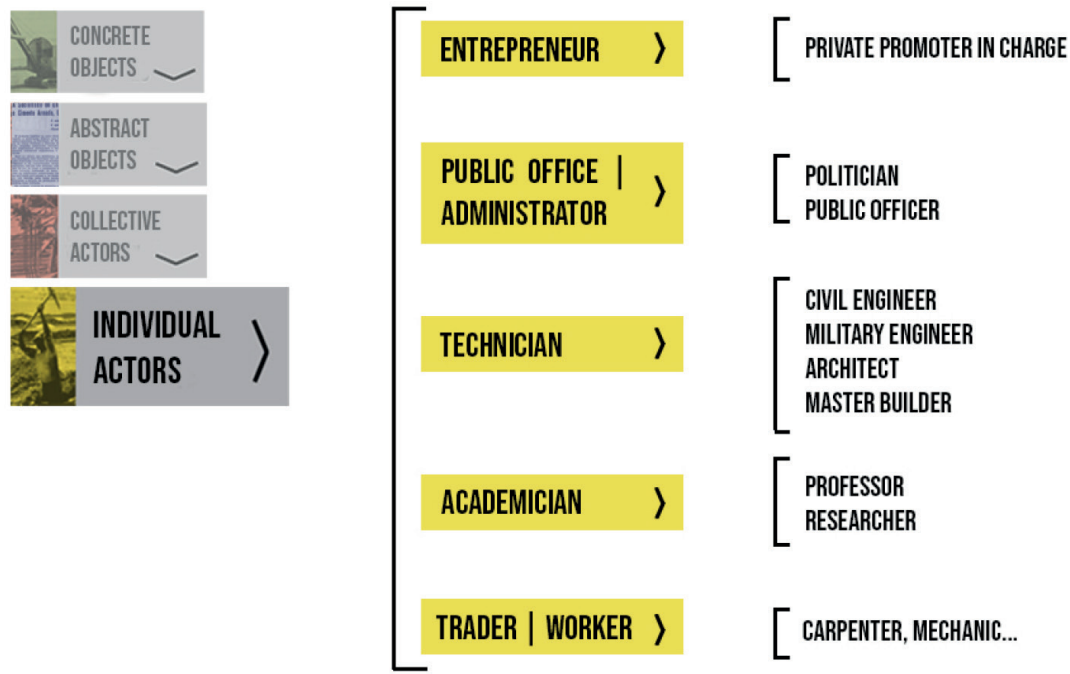

Figura 3 - Detalhe da árvore esquemática relativa à Coleção de Atores Individuais.

\section{2) Atores Coletivos}

A história da construção é também uma história das organizações que a compõem, e, nesse sentido, a plataforma tem um perfil das empresas, das associações - empresariais e de trabalhadores - e das instituições públicas de administração e de ensino que moldaram a trajetória do setor durante os dois últimos séculos. De forma a considerar essa rede de influências, foram definidas as seguintes subcategorias de Atores Coletivos: Firmas (empreiteiros, subempreiteiros, produtores, transformadores e vendedores de cal aérea, cal hidráulica, cimento Portland, outros cimentos, ferro/aço, agregados, materiais tradicionais, novos materiais); Instituições (públicas: administração pública, infraestruturas, educacionais; militares; privadas: religiosas, civis e educacionais); Associações (associações e sindicatos).

Considerando apenas os Atores, o estudo da história da construção ficaria incompleto sem a consideração dos artefatos por eles produzidos, sem o conhecimento das normas e dos processos construtivos ou sem informação sobre os diferentes materiais empregados. Daí a razão pela qual foi definido também o estudo de objetos concretos e objetos abstratos. 


\section{3) Objetos Concretos}

Para uma interpretação das transformações das culturas construtivas em Portugal durante os séculos XIX e XX, a coleção digital tinha de incluir as obras construídas, os materiais e as máquinas utlizados em sua execução. Nesse sentido, os Objetos Concretos foram classificados nas seguintes subcategorias: Obras Públicas e Privadas (edificações, infraestruturas, cofragens e andaimes); Materiais de Construção (cal aérea, cal hidráulica, cimento Portland, outros cimentos, agregados, pedra, tijolo, madeira, vidro, derivados petróleo); Máquinas e Ferramentas de Construção.

Desse modo, percorrendo os Itens, o usuário da plataforma pode conhecer melhor o desenvolvimento do caminho de ferro e da rede de estradas; a localização das grandes infraestruturas (portos, pontes, barragens, empreendimentos urbanizados etc.) e das construções de referência em alvenaria, aço ou concreto armado; a localização dos fornos de cal, de tijolo; a localização das fábricas de cal hidráulica e de cimento Portland; as empresas de distribuição ou, ainda, as características da maquinaria usada pela primeira vez em território português.

\section{4) Objetos Abstratos}

Com os metadados da plataforma e a facilidade de produzir visualizações que facilitam a pesquisa, é possível olhar para os objetos de estudo da história da construção que remetem à produção de conhecimento técnico e científico, à propaganda e à publicidade. Nesse sentido, foram criadas as subcategorias: Publicações (ciência dos materiais, processos construtivos, história da construção); Legislação (leis e regulamentos); Patentes; Processos Construtivos (alvenarias, betão armado, betão pré e pós-esforçado, aço, estruturas mistas).

Para todas essas categorias e subcategorias, foram utilizados os seguintes tipos de Itens já oferecidos de base pelo Omeka: Sound, Still Image, Video, Person, Text. Como complemento, foram desenvolvidos novos tipos de Itens relacionados especificamente com a história da construção, a saber: Construction Work, Building Material, Building Machine, Legislation, Patent, Study, Firm, Institution, Association, Structural System. No tipo Study, foram incluídas as várias subcategorias de publicações já mencionadas. Na respectiva página de gestão, cada Item passou a conter várias abas: Dublin Core, Item Metadata Type (associa o tipo de Item ao objeto digital), Files (aceita um número indefinido de ficheiros), Tags (etiquetas associadas a assuntos), Maps (localiza o Item no espaço) e Item Relations (as relações entre Itens ou outros já usados pelo vocabulário controlado). Refira-se, igualmente, que todos os Itens podem ter quatro formatos — texto, som, imagem e vídeo. 


\section{FERRAMENTAS DIGITAIS PARA A UTILIZAÇÃO E A GESTÃO DA PLATAFORMA}

Wa plataforma, sobretudo por meio dos vários módulos de extensão, os dados podem ser (Timelines) permite sobrepor processos de macroescala, como as mudanças de regime, a processos de microescala, como a produção de legislação relacionada com dado tema. É possível, igualmente, sobrepor em diversas camadas as mudanças no interior do próprio campo, como os momentos de inovação no nível da maquinaria ou dos materiais. Em simultâneo, os mapas gerados e os instrumentos de visualização espacial possibilitam ainda uma exploração dos dados em uma perspetiva temporal, ajudando a criar quadros, tabelas e textos de síntese das mudanças na cultura construtiva.

Os dados recolhidos servem a várias tarefas depois de incluídos na plataforma. Por um lado, as tabelas e os gráficos ajudam o utilizador a perceber as mudanças e continuidades da história da construção em sua relação com os processos sociais e políticos. Por outro, os dados podem também ser trabalhados externamente depois de exportados em formato $\mathrm{CSV}_{1}{ }^{16}$ por meio do módulo de extensão CSV Export Format. A partir daí, é possível fazer sua análise recorrendo a instrumentos de estatística ou usando a linguagem de programação $R_{1}{ }^{17}$ por exemplo. Considerando sua capacidade para explorar relações por meio do módulo de extensão Relations, os dados podem ser exportados para um programa de análise de redes (Ucinet ou Gephi, por exemplo). Para além das representações das relações já produzidas automaticamente pela plataforma por meio do módulo de extensão Avant Relationships, com as técnicas da análise de redes será possivel produzir outros esquemas, para além dos diagramas das principais relações entre Atores e Objetos oferecidos pela plataforma. Poderá ser o caso, por exemplo, da análise de questões de gênero e de classe ou de perceber como os vários Atores Individuais e Coletivos influenciaram a legislação e relacionaram-se com o campo do ensino, da publicidade e do comércio externo. Todas essas ferramentas digitais têm, para além de inegáveis virtudes heurísticas, a capacidade de desenvolver uma análise exploratória a uma escala inédita, propícia a potenciar a cooperação internacional do projeto.

\section{A PRIMEIRA EXPOSIÇÃO DISPONÍVEL NA PLATAFORMA}

$\mathrm{T}$ endo em consideração os procedimentos de estruturação da plataforma que acabam de ser descritos, é possível passar à apresentação da primeira exposição virtual, que se encontra na fase final de sua versão beta. Dedicada a cerca de duas dezenas de grandes 
empresas de obras públicas em atividade em Portugal no final século XX (Building Contractors in Portugal at the Turn of the Millennium), representativas da realização das infraestruturas de Portugal durante todo o século XX, constitui um pretexto para explorações de natureza diversa. É possível, assim, conhecer as grandes obras executadas por essas construtoras por todo o território português, não só durante o Estado Novo como pelos vários governos após o 25 de Abril, em particular as grandes construções realizadas com fundos da Comunidade Europeia. Começando pelo perfil histórico de cada empresa, o usuário é convidado a explorar uma seleção de obras que essa empresa executou. Para cada construção, é então possível passar ao conhecimento das instituições que foram os donos dessa obra, os arquitetos, os engenheiros e outros técnicos que nela trabalharam, assim como as publicações produzidas em relação a essa construção. Esse primeiro produto disponibiliza ao utilizador um conjunto de produtos muito diversificados:

1. gráficos com a cronologia de todas as obras realizadas por dada construtora (Figura 4);

2. imagens históricas e documentos digitalizados, registro de áudio e vídeo que caraterizam cada empresa (Figura 5);

3. textos com perfis históricos das empresas, biografias dos fundadores e colaboradores das empresas e seleção representativa de obras realizadas por cada empresa (Figura 6);

4. gráficos interativos de redes de empresas, atores e obras (Figura 7);

5. mapas interativos georreferenciados, com a possibilidade de sequenciá-los no tempo (Figura 8).

E ainda publicações científicas sobre o processo de construção das obras apresentadas e hiperligações a outros arquivos digitais.

Essa primeira exposição permitiu avaliar as potencialidades da plataforma ao juntar fontes de natureza muito diversa em uma mesma grelha de análise. Selecionaram-se fontes de origens variadas e empregaram-se diferentes formatos e suportes, para assegurar o uso da plataforma de um modo interativo por audiências especializadas e pelo público em geral. Os instrumentos digitais possibilitaram também encontrar as referências a essas empresas entre os mais de 100 Gigabytes de fontes digitalizadas, de forma mais sistematizada e eficiente no nível da gestão do tempo. Apesar da importância das fontes digitais, é previsto um investimento adicional no nível das fontes secundárias e o recurso, em um futuro próximo, a registros de história oral. 
The timeline of works done by/with the collaboration of Teixeira Duarte S.A.

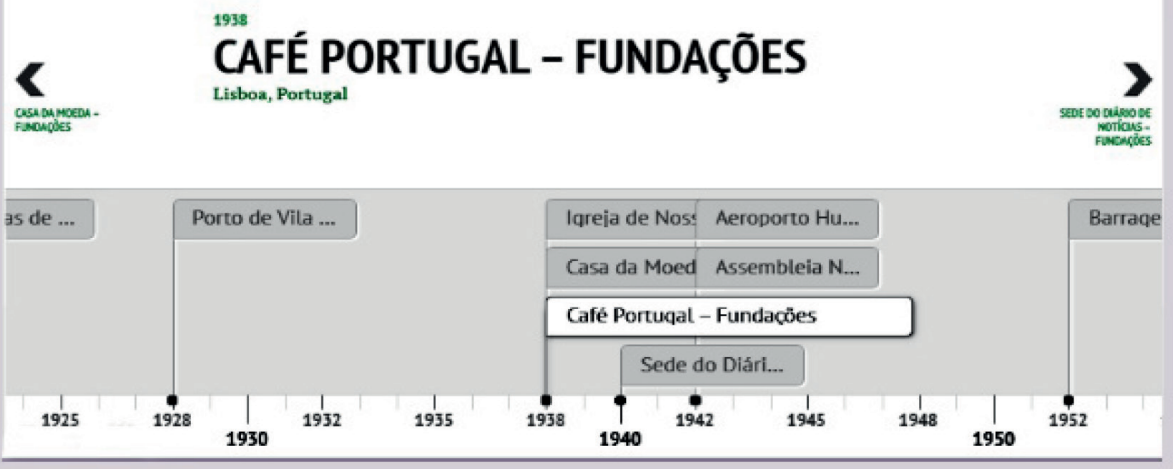

Figura 4 - Gráfico com a cronologia das obras executadas por umas das empresas construtoras que fazem parte da primeira exposição virtual.

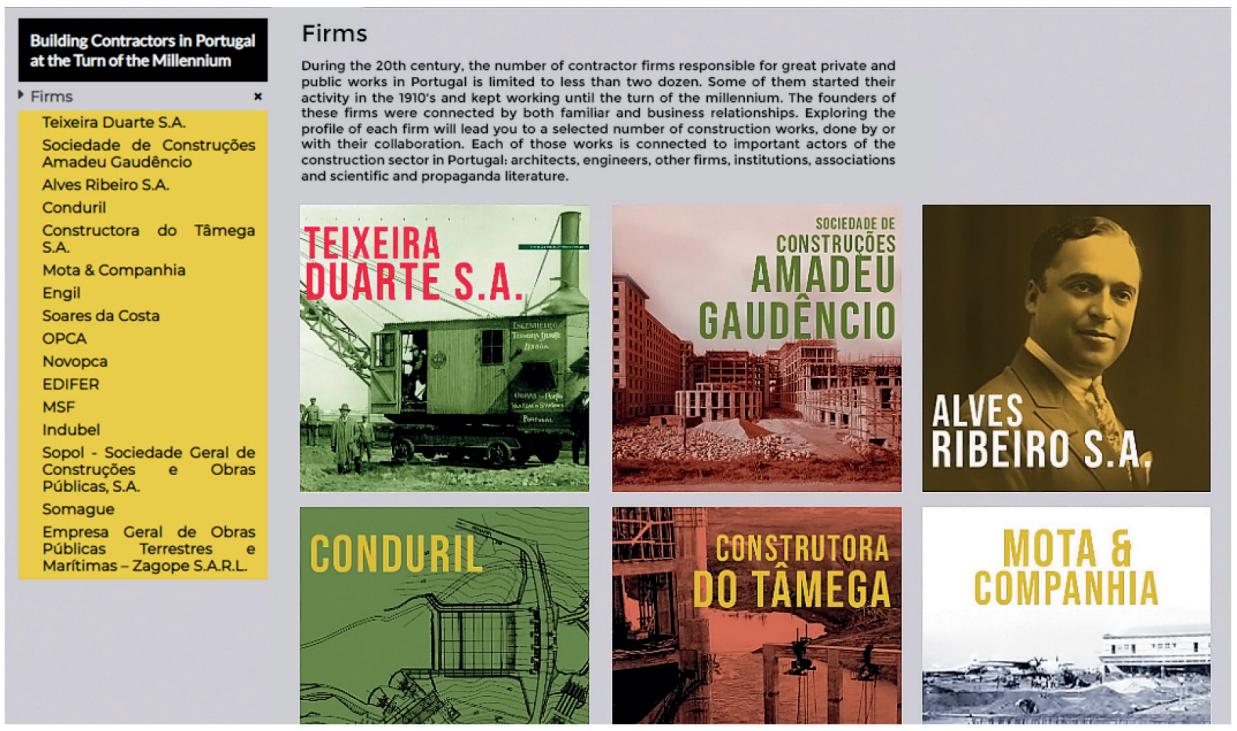

Figura 5 - Página do menu das várias empresas construtoras que o usuário pode consultar na primeira exposição virtual. 


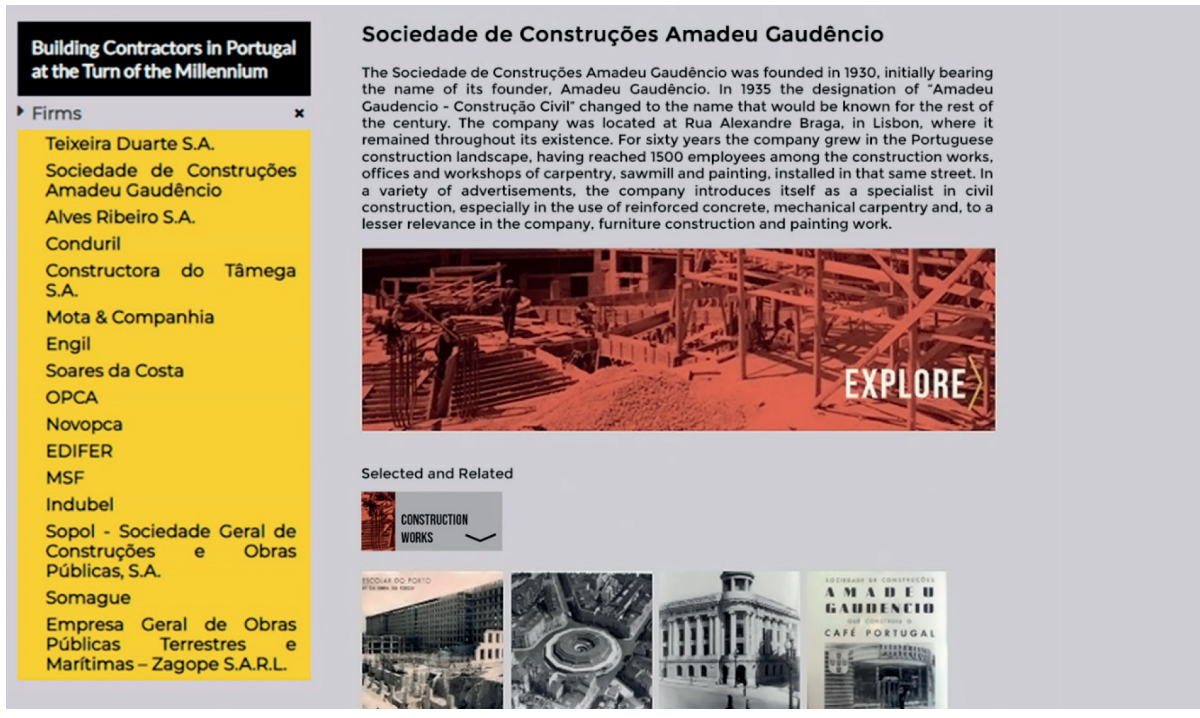

Figura 6 - Página relativa a uma das empresas construtoras, em que o usuário pode conhecer o perfil histórico da empresa e um grupo selecionado de obras por ela realizado.

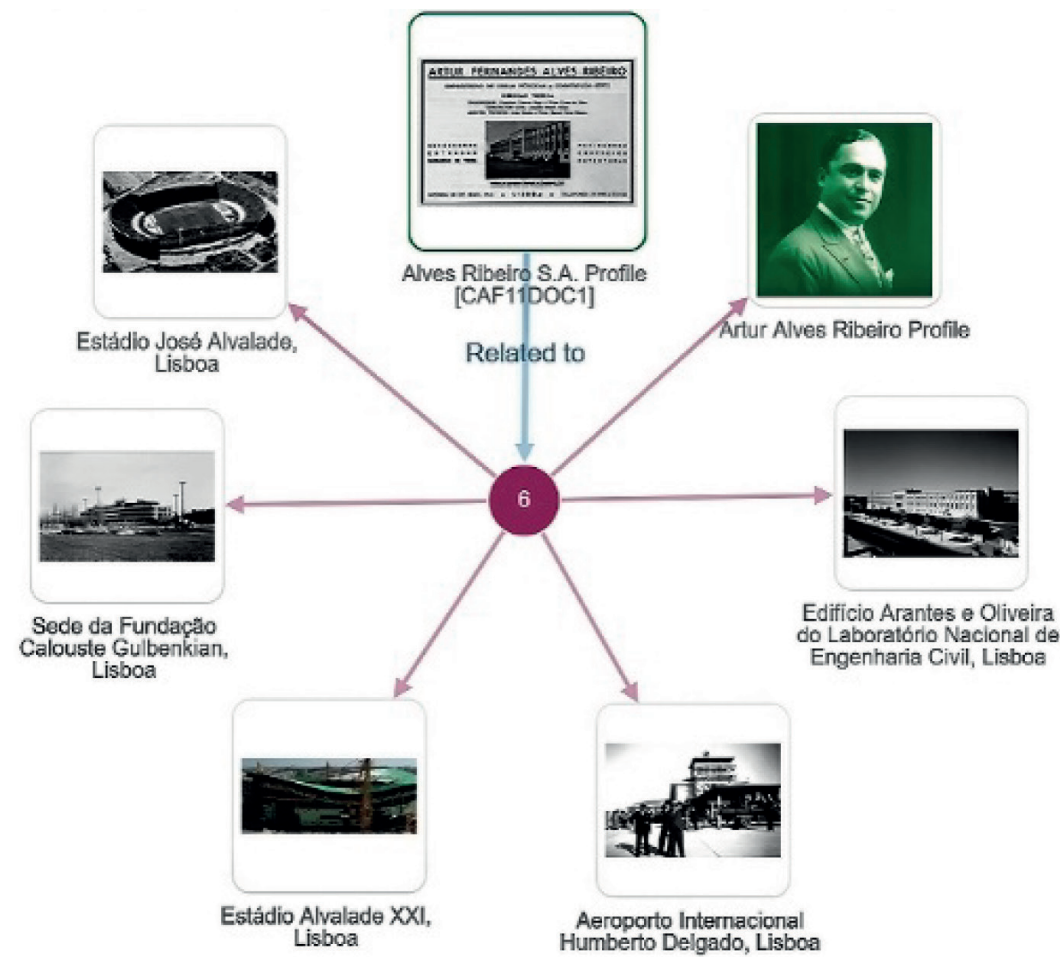

Figura 7 - Gráfico da rede criada por uma construtora, por seu empresário e por um conjunto de obras selecionadas. 


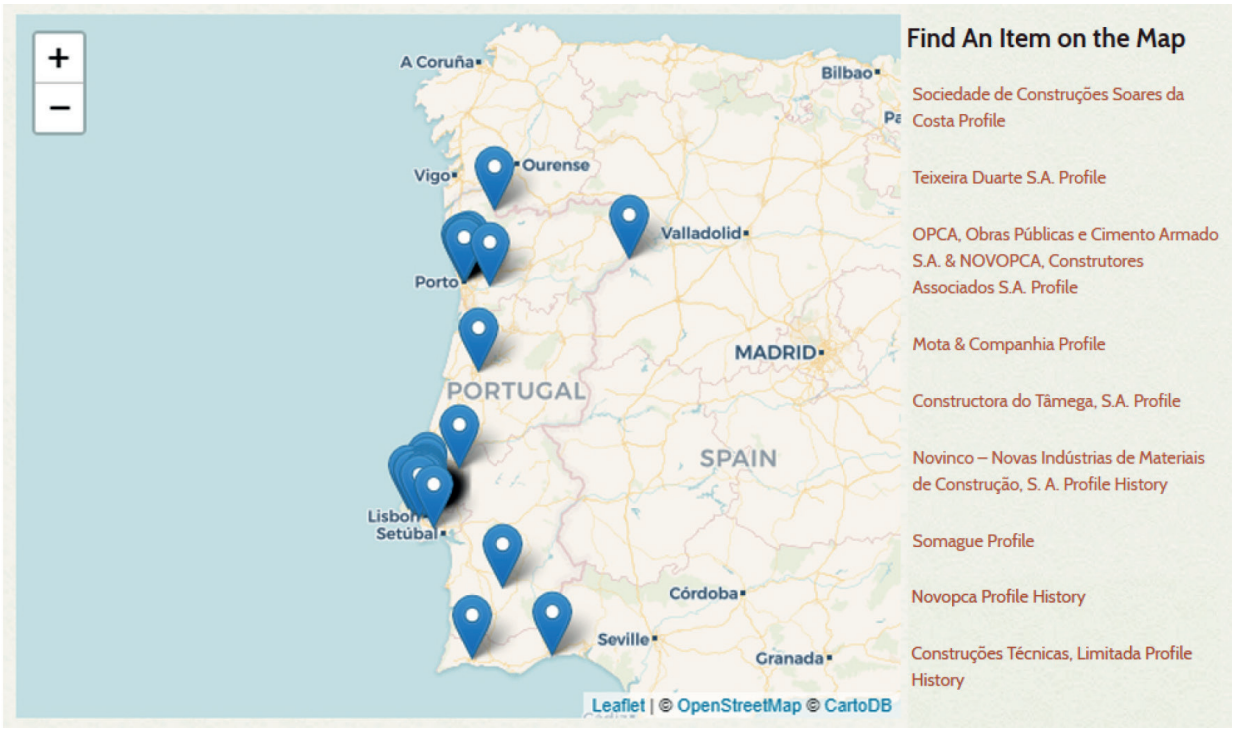

Figura 8 - Mapa interativo georreferenciado com a seleção de obras de cada empresa.

\section{DESENVOLVIMENTOS FUTUROS E ALGUMAS CONCLUSÕES}

D entro dos objetivos a curto prazo do projeto, inclui-se a criação da segunda exposição virtual a disponibilizar na plataforma e para a qual já se está a trabalhar. Será dedicada às redes de engenheiros, de empresas e instituições envolvidas na construção das linhas de caminho de ferro, dos portos e dos faróis que foram realizados por todo o território de Portugal durante a segunda metade do século XIX. No que toca a procedimentos de gestão, para poder avaliar o impacto dos conteúdos digitais produzidos no âmbito do projeto e disponíveis em linha, procede-se, atualmente, à implementação de rotinas de manutenção. Para a avaliação do impacto e do desempenho, estão previstas as seguintes ferramentas: métodos quantitativos, como o Google Analytics; inquéritos aos utilizadores a partir da abertura de uma nova janela acessível ao usuário; o exame da localização, do tempo de utilização e do número de visitas de páginas. Pretende-se adotar ainda métodos qualitativos, como a realização de entrevistas, a caracterização do perfil dos utilizadores e a análise dos conteúdos das citações. Por último, será testada a presença do projeto nas redes sociais, como Facebook e Twitter, para avaliar o impacto do projeto em um espectro alargado ao público em geral, e não apenas acadêmico. 
No fim deste estudo, integrado em um número da revista dedicado às humanidades digitais, importa relembrar seu objetivo inicial, que era o de dar a conhecer e refletir sobre os procedimentos adotados na criação de uma plataforma digital de história pública. Podem-se encontrar muitos exemplos de plataformas em linha sobre os temas históricos mais diversos, porém é mais difícil encontrar uma descrição dos vários passos necessários para sua concretização - e este texto é focado, precisamente, no processo de criação, ao explicitar a sequência da metodologia seguida, guiada por critérios de sistematização e fiabilidade. Depois de apresentar as potencialidades dos instrumentos digitais para a disseminação dos resultados de investigação histórica em geral, foram analisados as singularidades, as limitações e os aspectos inovadores desses instrumentos ao serviço da história da construção, também ele um campo de conhecimento ainda pouco estudado em Portugal. Depois da descrição das fontes das coleções digitais a disseminar publicamente, passou-se à discussão aprofundada dos critérios e da metodologia usados na estruturação da plataforma. Por fim, apresentaram-se a primeira exposição virtual já produzida e os procedimentos de gestão em curso.

Essa sequência de exposição analítica de um projeto de humanidades digitais, apesar de ainda não estar terminado, propõe-se como um formato de documento de discussão analítica válida também para outros projetos de disseminação histórica em curso. Por essa razão, os primeiros resultados que exploram os metadados e os conteúdos do projeto PTBuilds, que aqui acabam de ser apresentados, pretendem servir como estímulo não apenas para conceber novos projetos digitais internacionais no âmbito da história da construção, como também para melhorar os procedimentos da criação de plataformas em linha de acesso público nos vários campos de estudo da história.

\section{NOTAS}

10 estudo em que se baseia o presente artigo é financiado por fundos de Portugal por meio da Fundação para a Ciência e Tecnologia (FCT), I.P., no âmbito do projeto "Portugal Builds - plataforma digital de conhecimento da história das culturas construtivas em Portugal, séculos XIX-XX", Ref. PTDC/ ART-DAQ/28984/2017.

2 A expressão "Portugal Builds" inspira-se na força expressiva do título do livro Brazil builds: architecture new and old, 1652-1942, de Philip Lippincott Goodwin, dedicado ao Brasil e publicado em Nova York, em 1943. 0 projeto, iniciado operativamente em abril de 2019 e a concluir em setembro de 2021, é coordenado por João Mascarenhas Mateus (Ciaud - Faculdade de Arquitetura da Universidade de Lisboa) e por Sandra M. G. Pinto (Cham - Universidade Nova Lisboa), e envolve igualmente Daniel Ribeiro Alves, do Instituto de História Contemporânea (IHC - Universidade Nova de Lisboa). A parte gráfica tem sido assegurada por Júlia Lyra, e a investigação complementar de conteúdos, por Manuel Caiado. 
3 Omeka é um recurso em acesso aberto disponível na internet que permite a publicação de plataformas destinadas à partilha de coleç̃̃es digitais e à criação de exposições online baseadas em repositórios de metadados, desenvolvida pela Corporation for Digital Scholarship, pelo Roy Rosenzweig Center for History and New Media e pela Universidade de George Mason, dos Estados Unidos (Disponível em: <https://omeka.org/>. Acesso em: 16 dez. 2019).

40 endereço eletrônico da plataforma é <https://www.portugalbuilds.org $>$. A primeira exposição virtual, de que neste texto se apresentam imagens de ecrã em sua primeira versão testada (versão alfa), será liberada em sua versão beta para divulgação pública até 31 de dezembro de 2019.

5 Segundo a Pordata (Base Dados Portugal Contemporâneo. Disponível em: <http://www.pordata.pt>. Acesso em: 16 dez. 2019), o setor da construção e das indústrias transformadoras contribuiu em 10,7\% para 0 total das emissões portuguesas de gases com efeito estufa. 0 valor mais recente (2018) do PIB da construção em Portugal é de 1902,30 milhões de euros, segundo o sítio <https://pt.tradingeconomics.com>. Segundo o relatório "O sector da construção em Portugal - 2019 - 10 semestre", disponível no sítio do Instituto dos Mercados Públicos do Imobiliário e da Construção, o setor da construção contou com 306.100 indivíduos ,e a população ativa de Portugal, com 5.245.000 indivíduos.

6 Disponível em: <http://seshatdatabank.info/>. Acesso em: 16 dez. 2019.

7 Disponível em: <https://pro.europeana.eu.do>. Acesso em: 16 dez. 2019.

8 Disponível em: <http://history-lab.org/analytics>. Acesso em: 16 dez. 2019.

9 Para a análise de redes aplicada à história, consulte-se o sítio da Historical Network Research (<historicalnetworkresearch.org>), que tem uma extensa lista bibliográfica. 0 interesse pelas questões do espaço na história também tem conhecido um crescimento acentuado nos últimos anos - aqui, apenas nos interessa, para já realçar, as possibilidades de visualização, sem recorrer a instrumentos analíticos como os Sistemas de Informação Geográfica (SIGs).

10 Por exemplo, o sítio da Construction History Society, do Reino Unido (<http://www.constructionhistory. co.uk>), e o sítio da Sociedade Portuguesa de Estudos de História da Construção (<http://www.spehc.pt>) espelham bem essa nova dinâmica de pesquisa transnacional.

11 Consultem-se, entre muitos outros, Histories of the National Mall (<http://mallhistory.org >); DIY History (<http://diyhistory.lib.uiowa.edu/about-the-project $>$ ); Marshall M. Fredericks Sculpture Museum (<http:// omeka.svsu.edu>).

12 Disponível em: <https://www.europeana.eu/portal/en>. Acesso em: 16 dez. 2019.

130 Projeto PTBuilds segue-se ao Projeto Exploratório Investigador FCT, denominado "From Lime to Portland cement. Construction history and building cultures in contemporary Portugal" (Ref. IF/00792/2014/CP1259/ CT0001), coordenado por João Mascarenhas-Mateus no Ciaud - Faculdade de Arquitetura da Universidade de Lisboa, entre janeiro de 2016 e janeiro de 2020, financiado pela FCT, de Portugal. Disponível em: <http:// ptbuilds20.fa.ulisboa.pt>. Acesso em: 16 dez. 2019.

14 Reclaim Hosting nasceu em 2013, com o objetivo principal de ajudar universidades a desenvolver seus próprios projetos em linha, e encontra-se sediada em Fredericksburg, Virginia (<https://reclaimhosting.com>).

15 Os elementos centrais de metadados do Dublin Core formam um vocabulário genérico de 15 propriedades, usado para descrever recursos (digitais, nesse caso), fazendo parte de um vocabulário de metadados 
mais amplo. Como referido no texto, o emprego desses elementos na plataforma contribui para a fiabilidade da pesquisa e da análise. As 15 propriedades do Dublin Core são: Title, Subject, Creator, Description, Publisher, Contributor, Date, Type, Format, Identifier, Source, Language, Relation, Coverage e Rights. Para a definição dos elementos, consulte-se: <https://www.dublincore.org/specifications/dublin-core/dces/>.

160 formato CSV (comma-separated values), que separa valores com vírgulas, é amplamente aceito em programas de análise e de gestão de dados. O CSV usa-se não só em programas de estatística, folhas de cálculo ou bases de dados, como também na análise de redes, motivo pelo qual os dados são apresentados na plataforma com esse formato.

17 A linguagem de programação R, criada em 1993, é particularmente usada na análise estatística e na manipulação de dados e de gráficos. Essa linguagem, de acesso gratuito, é amplamente usada nas ciências sociais, na ciência de dados e na análise matemática.

\section{REFERÊNCIAS BIBLIOGRÁFICAS}

AA.VV. Digital history and argument. Roy Rosenzweig Center for History and New Media, 13 nov. 2017. Disponível em: <https://rrchnm.org/argument-white-paper/>. Acesso em: 25 jun. 2019.

BEARMAN, P. Big data and historical social science. Big Data \& Society, v. 2, n. 2, p. 1-5, 2015.

BERETTA, F. L'interopérabilité des données historiques et la question du modèle: I'ontologie du projet SyMoGIH. In: JUANALS, B.; MINEL, J.-L. (Org.). Enjeux numériques pour les médiations scientifiques et culturelles du passé. Paris: Presses Universitaires de Paris Nanterre, 2017. p. 87-127.

BOLDIZZONI, F. The poverty of Clio: resurrecting economic history. Princeton: Princeton University Press, 2011.

BRAUDEL, F. Civilização material, economia e capitalismo. Lisboa: Editorial Teorema, 1992. 3 v.

DAVIS, H. The culture of building. Oxford: Oxford University Press, 2006.

DE PAIVA, V.; OLIVEIRA, D. A. B.; HIGUCHI, S.; RADEMAKER, A.; DE MELO, G. Exploratory information extraction from a historical dictionary. In: 2014 IEEE $10^{\text {th }}$ INTERNATIONAL CONFERENCE ON ESCIENCE, 2, 2014, escience. Proceedings..., 2014, p. 11-18.

EDELSTEIN, D.; FINDLEN, P.; CESERANI, G.; WINTERER, C.; COLEMAN, N. Historical research in a digital age: reflections from the mapping the republic of letters project. The American Historical Review, v. 122, n. 2, 2017.

FLANDERS, J. ; JANNIDIS, F. Gentle introduction to data modelling. In: FLANDERS, J.; JANNIDIS, F. (Ed.). The shape of data in digital humanities: modeling texts and text-based resources. Londres: Routledge, 2018.

GULDI, J.; ARMITAGE, D. The history manifesto. Cambridge: Cambridge University Press, 2014.

KRAKAUER, D. C.; GADDIS, J. L.; POMERANZ, K. (Ed.). History, big history, \& metahistory. Santa Fé (EUA): Santa Fe Institute Press, 2018.

LEMERCIER, C. Une histoire sans sciences sociales?. Annales: Histoire, Sciences Sociales, v. 70, n. 2, $2015 \mathrm{a}$.

Formal network methods in history: why and how?. In: FERTIG, G. Social networks, political institutions, and rural societies. Turnhout, Bélgica: Brepols Publishers, 2015b. p. 281-310. 
MASCARENHAS-MATEUS, J. Culturas construtivas em Portugal e no Brasil: contributos para uma análise diacrónica. In: RIBEIRO, N. P. (Org.). In: I CONGRESSO INTERNACIONAL DE HISTÓRIA DA CONSTRUÇÃO LUSO-BRASILEIRA, 2013, Rio de Janeiro. Anais... Rio de Janeiro, 2013. (CD-ROM). Work in progress: current research in construction history. From lime to Portland cement. Construction history and building cultures in contemporary Portugal. Construction History: International Journal of the Construction History Society, v. 31, n. 1, p. IX-X, $2016 a$.

. Perduração de culturas construtivas tradicionais em tempos de progresso. História da construção em Portugal na década de 1950. In: $2^{\circ}$ CONGRESSO INTERNACIONAL DE HISTÓRIA DA CONSTRUÇÃO LUSO-BRASILEIRA, 2016, Porto. Actas... Porto: Faup, 2016b. p. 579-591.

2018.

. (Ed.). História da construção em Portugal: consolidação de uma disciplina. Lisboa: By the Book,

MORLEY, J. Building themes in construction history: recent work by the Delaware Valley Group. Construction History, v. 3, p. 13-30, 1987.

PUTNAM, L. The transnational and the text-searchable: digitized sources and the shadows they cast. The American Historical Review, v. 121, n. 2, p. 377-402, 2016.

SCHREIBMAN, S. S.; SIEMENS, R.; UNSWORTH, J. (Ed.). A new companion to digital humanities. Chicester: John Wiley \& Sons, 2016.

SHINTAKU, M. et al. Guia do usuário do Omeka. 2018. Disponível em: <http://repositorio.enap.gov.br/handle/1/3162>. Acesso em: 15 mar. 2019.

SIMMEL, G. On individuality and social forms. Chicago: Chicago University Press, 1971.

STRAUSSER, B. J.; EDWARDS, P. N. Big data is the answer... But what is the question?. Osiris, v. 32, n. 1, p. 328-345, 2017.

STRUCK, B.; FERRIS, K.; REVEL, J. Introduction: space and scale in transnational history. The International History Review, v. 33, n. 4, p. 573-84, 1º dez. 2011.

TOSTÕES, A. A idade maior, cultura e tecnologia na arquitectura moderna portuguesa. Porto: Faup, 2015.

WEBER, M. Economy and society: an outline of interpretative sociology. Berkeley: University of California Press, 1978. 2 v. 